\title{
NOTES OF THREE CASES
}

\section{Demonstrated at special M.R.G.P. classes at the Brompton Hospital.}

\author{
By MAURICE DAVIDSON, M.A., M.D., F.R.C.P. \\ (Physician to Brompton Hospital, Senior Physician to the Miller General Hospital, \\ Consulting Physician to the L.C.C.)
}

\section{A case of Chronic Pneumothorax associated with Asthma.}

A girl aged 26 was sent to me at the Brompton Hospital by Dr. Gregory Kayne for further opinion and advice. She had been subject to attacks of asthma since the age of seven. She had been to various hospitals for advice and treatment : up to a recent date no gross structural changes in the lungs had been shown. A radiogram of the chest taken in I936 showed no appearances outside the normal limits of variation. There had been considerable loss of weight (from 7 st. $4 \mathrm{lbs}$. in April, I940, to 4 st. I3 lbs. in February, I94I). According to her own account she had been in a shelter one night during a bombing attack, when she was seized with very severe dyspnœa, far worse than she had ever experienced in the worst of her asthmatic attacks. She was seen by Dr. Kayne on 8th November, I940, and he wrote to me: "The plain radiograph shows appearances on the right side which first I thought to be due either to large emphysematous bullæ or to congenital cystic disease; I thought it probable that at the base there might be in addition a small spontaneous pneumothorax. . . . I should be interested to hear what you think about her."

When I first saw this patient, I was struck by her smallness and her extremely thin appearance. Her weight, taken in the out-patient department, was 5 st. I2 lbs. (in light clothes). Examination of the chest showed a fairly large area of hyper-resonance in the lower half on the right side, the breath sounds over this area being, however, loud and distinct. On the left side the corresponding area of the chest wall showed some retraction. On the right side, behind, there was a very large area of hyper-resonance occupying the upper two-thirds of the chest, the breath sounds in this region being much diminished. A few rhonchi were heard at the left base. A plain radiogram showed the appearances indicated in the accompanying diagram (see Fig.). It will be noticed that the right side of the chest contains numerous large air spaces (marked A in the diagram), and that there is some displacement of the heart to the left side. From the history of a sudden and severe attack of dyspnœa, and from the slight cardiac displacement, I concluded that these appearances were most probably due to the occurrence of spontaneous pneumothorax, though there was a variety of opinions expressed at the time by several who saw the case with me, some inclining to the view that the air spaces were associated with cystic disease of the lung. My colleague Dr. Rawlinson was of the opinion that the X-ray appearances were indicative of a complete pneumothorax on the right side with adhesions.

The patient was admitted for further investigation, and was later seen by my surgical colleague, Mr. R. C. Brock, who advised a thoracoscopic exploration. The thorascope was introduced in the ninth interspace in the posterior axillary line. The appearances over the lower and middle lobes did not suggest the presence of cystic disease, and were thought to be due to a large pneumothorax. A wide band of adhesions prevented any view of the upper lobe. The thorascope was then reintroduced anteriorly in the second interspace, and an oval hole, 1 inch by $\frac{3}{4}$-inch in size, was seen, situated, so far as could be made out, either in a band of adhesions or else in the wall of a large cyst. The patient was now given a cigarette and asked to inhale the smoke; none of the smoke could be seen through the thorascope, and it was therefore concluded that no communication was present between the pleural cavity and any of the divisions of the bronchi. There was nothing, therefore, in these appearances to suggest that cystic disease of the lung was present, and the diagnosis of pneumothorax was confirmed to our satisfaction. The edges of the hole were painted with a 2 per cent. solution of silver nitrate, introduced posteriorly on a swab. The anterior cavity was shown to communicate with the posterior and lower pneumothorax cavity. 
The patient's subsequent progress was satisfactory, though her recovery was somewhat lengthy owing to various complications such as surgical emphysema, and the development of a sterile pleural effusion. On several occasions some air had to be withdrawn from the chest because of the patient's dyspnœa, but the hole in the visceral pleura gradually diminished in size, complete closure being further aided by the introduction of a small quantity (m.5) of a Io per cent. solution of silver nitrate into the pleural cavity. The dyspnœa became progressively less, and the patient's general condition gradually improved, her weight on discharge from the hospital in June, I94I, having risen to $7 \mathrm{st}$. I lb.

$\mathrm{X}$-ray examination at this stage showed that the right lung had completely re-expanded. She has, since then, attended the out-patient department for the treatment of the asthmatic attacks, which still continue, though they are not usually of great severity. She has obtained benefit from a course of auto-hæmotherapy, six injections of whole blood having been given at weekly intervals. At no time have tubercle bacilli been found in the sputum. There has, so far, been no recurrence of the pneumothorax.

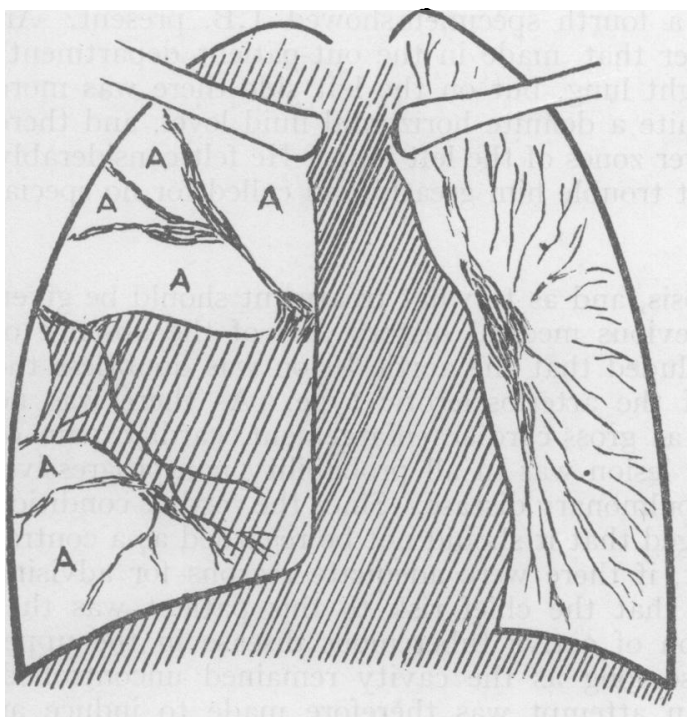

POSTERO-ANTERIOR VIEW

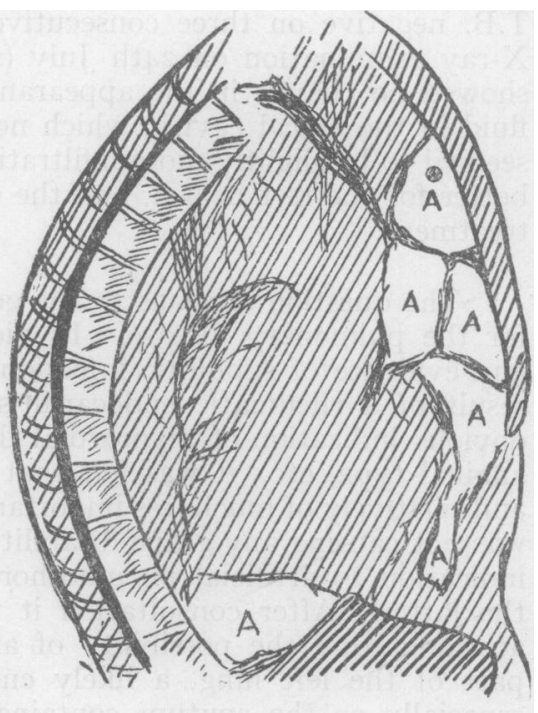

LATERAL VIEW

Diagram of X-Ray Films, illustrating the case of Chronic Pneumothorax.

\section{A case of Pulmonary Tuberculosis Aortic Regurgitation.}

The combination of rheumatic morbus cordis with pulmonary tuberculosis in the same individual, though not perhaps a rarity, is sufficiently uncommon to call forth some remark. This patient, a man of forty-seven, came to the out-patient department at Brompton on account of a cough which had persisted for five or six months, following an attack of so-called influenza. He had a fair amount of sputum, which had on one occasion been slightly bloodstained, and was complaining of night sweats, general lassitude, and especially breathlessness on exertion. It was mainly on account of this last symptom that he had had to give up his work as an aircraft electrician.

In 1932 (nine years ago), he had had an attack of rheumatic fever and had been in bed for nine months. In 1922 (nineteen years ago), he had had pleurisy with effusion. On clinical examination of the chest there was no obvious evidence of cardiac enlargement. The apex-beat was in the fifth interspace 4 to $4 \frac{1}{2}$ inches from the mid-sternal line. The first sound was clearly audible ; a diastolic murmur could be heard in the mid-sternal region, conducted downwards and to the left toward the apex-beat. Little in the way of abnormal physical signs was found 
on examination of the lungs; there was some impairment of the percussion note below the left clavicle, but little alteration in the character of the respiratory murmur, and no added sounds. X-ray examination of the chest, however, showed some mottling in the right upper zone, as well as in the left upper and middle zones, with appearances suggestive of a cavity in the left upper lobe. He was admitted to the wards, partly because he seemed in need of a period of rest and recuperation, partly for demonstration purposes, for M.R.C.P. classes.

The main points in this case to which attention was directed were the assessment of his disability, the relation between the two conditions present, with special reference to the general prognosis, and the details of treatment. He remained an in-patient from 2 Ist July to I5th August. After the first two days, during which there was a slight evening rise of temperature (99-IO0), he was afebrile, except for an evening rise to $99^{.2}$ on 3 oth August, and to Ioo.8 on 3Ist August. The pulse rate averaged 70-80. There was no alteration in the auscultatory signs. The blood-pressure readings were 130 (systolic), 40 (diastolic). The Wassermann and Kahn reactions were negative. The erythrocyte sedimentation rate was $58 \mathrm{~mm}$ (Westergren) at the end of one hour. The sputum, which was small in amount ( 2 or 3 drams daily), was T.B. negative on three consecutive occasions; a fourth specimen showed T.B. present. An X-ray examination on 24th July (six weeks after that made in the out-patient department) showed no change in the appearances in the right lung, but on the left side there was more fluid in the apical cavity, which now showed quite a definite horizontal fluid level, and there seemed to be slightly more infiltration of the lower zones of the left lung. He felt considerably better for the rest in bed, and the cough did not trouble him greatly and called for no special treatment.

The question arose as to the general prognosis, and as to what treatment should be given for the pulmonary disease. In view of the previous medical history and of the absence of any evidence of syphilitic infection, it was concluded that the aortic lesion was doubtless the result of a rheumatic endocarditis, and not of the arteriosclerotic type. As there was no obvious indication of myocardial damage, such as gross cardiac enlargement, cardiac pain of anginal type, etc., it was felt that the valvular lesion was in all probability non-progressive, and relatively of much less importance than the pulmonary disease. Since the cardiac condition was not causing any grave disability, it was judged that it should not be regarded as a contraindication to artificial pneumothorax treatment, if there were adequate reasons for advising the latter. After consultation it was thought that the chief risk to this patient was that accruing from the possibility of an exacerbation of active tuberculous disease in the upper part of the left lung, a likely enough event so long as the cavity remained uncontrolled, especially as the sputum contained bacilli. An attempt was therefore made to induce an artificial pneumothorax on the left side. This unfortunately was a failure, the initial intrapleural pressures being -2 . . . I ; no air could be introduced, presumably owing to adhesions following the pleurisy in I922. Had it been possible to obtain a satisfactory pneumothorax, any temporary embarrassment of respiratory function associated with the valvular lesion would, it was thought, not prove serious or unmanageable.

There was one other point of interest in this case. The patient on one occasion complained of some pain in the eyes and also of defective vision, which he said was of old standing. $\mathrm{He}$ was sent to the Western Ophthalmic Hospital for opinion and advice on this matter. I am indebted to Mr. Stewart Macky for the following note: "He certainly has signs and effects of old iritis, but there is nothing active. There is no cataract, and the fundi are normal. The vision is $6 / 9$ in the right eye, and is reduced by posterior synechiæ and deposits on the lens to $6 / 24$ in the left eye. The iritis may have been tubercular, but there are no irritative signs."

\section{A case of acute Lymphadenoma.}

A boy of fifteen was sent to Brompton for advice on account of loss of weight, increasing weakness, and swelling of the right side of the neck due to enlargement of the cervical glands. He had been getting very much thinner during the last few months, his weight on 26th November being only 5 st. I2 lbs. He had complained of increasing dyspnca, especially on exertion, 
and also of discomfort in the region of the costal margin on the left side. On arrival at the out-patient department he appeared very pale and looked extremely ill. His temperature and respiration rate were not raised, but the pulse rate was I04. There was a large mass of glands to be felt in the anterior triangle of the neck on the right side ; the corresponding glands on the left side were also enlarged, but not to the same extent. The glands were discrete, soft, and easily movable. No glands were felt in the axillæ or in the inguinal regions. No abnormal physical signs were found in the chest. The abdomen was soft; the edge of the liver was palpable just below the costal margin; the spleen was considerably enlarged, the notch being easily felt. X-ray examination of the chest showed the heart to be globular in shape. No opacities suggestive of enlarged mediastinal glands were seen; no shadows of pathological significance were visible in the lung fields.

The comparatively short history of the illness and its somewhat acute character were suggestive of the diagnosis of acute leukæmia. The patient was referred to the Royal Cancer Hospital, where he was admitted the same afternoon under the care of my colleague Mr. Cecil Joll. A lymph node from the right side of the neck was removed for microscopic examination, and the following report on the section has been sent to me by the courtesy of Dr. F. H. Yates : "The microscopical picture is that of active lymphadenoma. The normal structure of the gland is entirely destroyed by proliferation of young collagen fibrils, distributed diffusely throughout the node. There is also active proliferation of the reticulum cells, with the formation of numerous giant cells of the Sternberg-Reed type, and the laying down of a considerable reticulin network. Numerous polymorphs are present, and in some areas many eosinophiles are seen. In a few minute areas necrosis is taking place." The blood picture showed no changes of material significance.

The diagnosis of Hodgkin's disease in this case rested, of course, upon the result of the blood examination, and on the characteristic histological changes seen in the lymph node. The clinical course of lymphogranuloma varies a good deal in individual cases, both acute and chronic forms being recognized, though the former is relatively uncommon. From the clinical point of view, the rapid onset of the illness with marked progressive emaciation and pallor, are, perhaps, more characteristic of acute lymphatic leukæmia, of which a provisional diagnosis had been made in this case, until blood examination showed the absence of any characteristic alteration in the white cells, and the true nature of the disease was revealed by biopsy.

It may be remarked that in those cases of Hodgkin's disease in which the glandular enlargement is chiefly in the mediastinum cervical gland affection is usually conspicuous by its absence ; indeed the presence of enlarged external lymph nodes is rather the exception than the rule. Conversely, in the common type of lymphadenoma, with multiple cervical glands and enlargement of the spleen, X-ray examination of the chest is likely, as in this case, to show little or nothing of pathological significance.

\section{RUTHIN CASTLE, NORTH WALES}

A Clinic for the diagnosis and treatment of Internal Diseases (except Mental or Infectious Diseases). The Clinic is provided with a staff of doctors, technicians and nurses.

The surroundings are beautiful. The climate is mild. There is central heating throughout. The annual rainfall is 30.5 inches, that is, less than the average for England.

The inclusive fees are from 15 guineas a week, according to the room occupied; rooms with bathroom are from 21 guineas. An examination and consultation fee of 15 guineas is charged on the first visit only. to doctor.

SPECIAL FEES FOR INVESTIGATION ONLY-30 GUINEAS, including stay up to 10 days and report 